Despite these potential pitfalls, we believe that the EULAR/ ACR criteria are a relevant step forward in appropriately defining who has SLE, and in teaching doctor and medical students how to approach a patient with possible SLE. The data have clearly demonstrated that ANA negative SLE is uncommon, and ANA are a useful entry criterion or screening parameter in case of suspected SLE. The analysis of interaction has important implications in that it has shown interactions within domains, upholding this concept, but not found significant associations between domains (or items in various domains). The latter in fact is an argument that SLE is indeed a disease, not a syndrome, and that it is the effector arm of the autoantibodies in any given SLE patient that underlies the variability.

Conclusions We will need more knowledge on autoantibodies, not less, and probably more clinical training, but this is more of a chance than a challenge. Above all, it has been remarkably easy to work together in this huge group, over the Atlantic and beyond, and I am deeply gratefully for the contribution of so many colleagues. This large team experience of collegiality and friendship will hopefully help the further worldwide collaboration that is necessary for advancing the field.

Acknowledgements The EULAR/ACR SLE classification project was equally supported by EULAR and ACR. Please refer to the publications for contributors to this effort.

\section{THE HISTORY OF LUPUS THROUGHOUT THE AGES}

Laurent Arnaud. Dept. of rheumatology, National French Reference Center for Auto-immune Diseases (RESO), INSERM 1109, Institut PACIFIC, Strasbourg, France

\subsection{6/lupus-2020-eurolupus.6}

The word lupus (Latin term for the wolf) is mentioned for the first time circa $850 \mathrm{AD}$. Originally, the term was used to describe lesions that were said to resemble wolves' bite. Early historical documents have suggested that the term lupus was used indistinctively during the middle-age and the Renaissance for many types of diseases characterized by ulcerous lesions, especially in the lower limbs. In 1230, Rolando of Parma distinguishes 'noli me tangere' (lesions located on the face) from lupula when the lesions are on the limbs. Four centuries later, there is still a great deal of confusion with Sennert, Culpeper \& Cole who mentioned (1661) that '[...] cancer can be divided into 3 species: into the cancer, [...] the noli me tangere $[\ldots]$ and lupus or the wolf if it is in the shins, ankle-bones and thighs'.

The true turning point in the history of lupus occurred in London in the beginning of the 19th century when Robert Willan and his student Bateman published the first atlases of skin diseases (1786-1817), containing the first known representation of a patient with lupus (figure 1). At that time, the disease was classified among 'tubercula' and the distinction between lupus vulgaris (skin tuberculosis) and cutaneous lupus in its modern sense was not clearly made until Keil in 1933. In 1850, the French dermatologist Cazenave mentions for the first time the term 'lupus érythemateux'. Kaposi describes the 'butterfly rash' in 1872 and identifies discoid lupus as a separate entity in 1875 . The history of lupus will take a new turn between 1872 and 1905, with major contributions from Kaposi, Sequiera \& Balean, and Osler who will enable the true recognition of the systemic nature of the disease

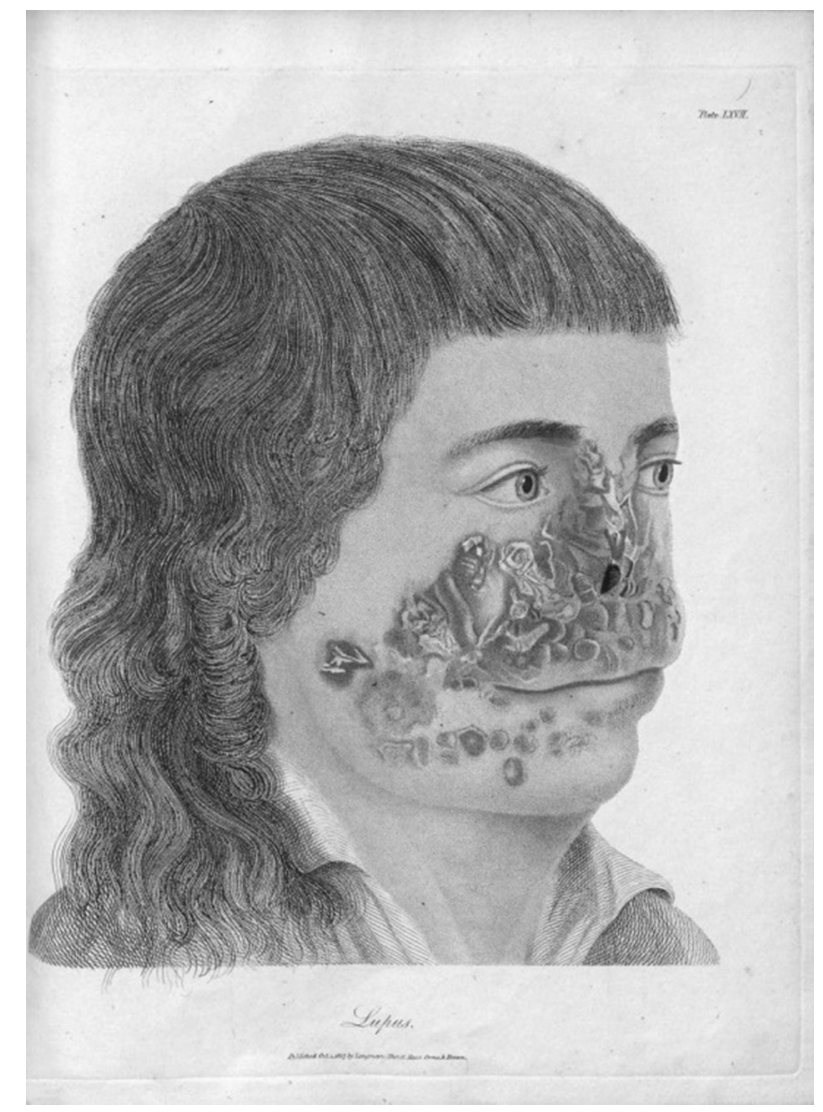

Abstract 16 Figure 1 Delineations of cutaneous diseases. Thomas Bateman, London (1918)

(Systemic Lupus Erythematosus). The modern history of lupus is notably marked by the discovery of lupus cells (LE cells) by Hargraves in 1948, of antinuclear antibodies by Miescher in 1954 and by the recognition of DNA as the main target of ANAs by Seligman in 1957.

Many treatments have been proposed for lupus throughout the ages, including the use of cauterization \& caustics (from the middle age to the modern era), radium (1900-1905), and even concentrated sun light \& UVs in London in 1905! Quinine was introduced in 1894 while most modern treatments for SLE appeared in the second half of the 20th century: glucocorticoids (1948-1952), quinacrine (1951), cyclophosphamide (1954), hydroxychloroquine (1956), azathioprine (1957) and mycophenolate mofetil (1980s). The end of the 20th century and the beginning of the 21st century are marked by a better understanding of the pathogenesis of the disease and the systematic evaluation of treatments, paving the way for improved diagnosis and better care for lupus patients.

\section{PATIENTS EXPECTATIONS, AND WHAT WE (CAN) DO ABOUT IT}

Alain Cornet, Kirsi Myllys, Anne Charlet, Annemarie Sluijmers, Marisa Costa, Elfried Wijsma, Jeanette Andersen. Lupus Europe, UK

\subsection{6/lupus-2020-eurolupus.7}

Background Lupus patient's expectations are no different than everyone else's: 'A better life'. But achieving it requires different steps because it entails (1) A prompt diagnosis, (2) Access to effective treatment with low side-effects, (3) Resolving 